\title{
Laboreal
}

Volume $16 \mathrm{~N}^{\circ} 1 \mid 2020$

Quando o trabalho real é tabu

\section{O amianto : glórias e tragédias de uma fibra} aterradora

\section{Introdução ao dossier}

El amianto : glorias y tragedias de una fibra aterradora

Introducción al dosier

L'amiante: gloires et tragédies d'une fibre effrayante

Introduction au dossier

Asbestos: glories and tragedies of a terrifying fiber

Dossier introduction

\section{Marianne Lacomblez e Augusto Rogério Leitão}

\section{OpenEdition}

\section{Journals}

\section{Edição electrónica}

URL: http://journals.openedition.org/laboreal/16183

DOI: $10.4000 /$ laboreal. 16183

ISSN: 1646-5237

\section{Editora}

Universidade do Porto

\section{Refêrencia eletrónica}

Marianne Lacomblez e Augusto Rogério Leitão, « $\mathrm{O}$ amianto : glórias e tragédias de uma fibra aterradora

Introdução ao dossier », Laboreal [Online], Volume 16 NN$^{0} 1$ | 2020, posto online no dia 01 julho 2020 consultado o 15 setembro 2020. URL : http://journals.openedition.org/laboreal/16183

Este documento foi criado de forma automática no dia 15 setembro 2020.

\section{(c) (i) \$}

Laboreal está licenciado com uma Licença Creative Commons - Atribuição-NãoComercial 4.0 Internacional. 


\title{
O amianto : glórias e tragédias de uma fibra aterradora Introdução ao dossier
}

\author{
El amianto : glorias y tragedias de una fibra aterradora \\ Introducción al dosier \\ L'amiante : gloires et tragédies d'une fibre effrayante \\ Introduction au dossier \\ Asbestos : glories and tragedies of a terrifying fiber \\ Dossier introduction
}

Marianne Lacomblez e Augusto Rogério Leitão

1 1. As comunidades humanas começaram, há vários milénios, a utilizar as fibras do amianto ou asbesto, uma rocha-minério, na fabricação de cerâmicas, de cores-tintas e de artefactos têxteis. Mas a nossa perceção atual desse mineral está sobretudo associada à existência e utilização de produtos em fibrocimento, e também, infelizmente, aos seus efeitos maléficos, individuais e coletivos.

2 Invenção (patenteada) do início do século XX, o fibrocimento está na origem da criação da sociedade Eternit-Suíça - 'Eternit' porque essa mistura de amianto e de cimento revestirá tais qualidades (durabilidade, resistência térmica e mecânica, boa qualidade isolante, incombustibilidade, etc.) que se acreditou o seu uso ser "para a eternidade". o grupo empresarial foi detido, até meados de 1980, pela família Schmidheiny, nome que, como veremos, se tornará célebre por muitas más razões. A Eternit instalará fábricas por toda a Europa, produzindo telhas, depósitos de água e tubos para canalizações. Porém, o grande desenvolvimento da produção e comercialização dos produtos com amianto terá lugar após a II Guerra mundial, no contexto da dinâmica da reconstrução, proporcionando, aliás, novos produtos (placas de revestimento e de isolamento térmico, têxtil amianto, ...) e novas utilizações (discos de embraiagem, pastilhas de travão de veículos, ...). 
3 Simultaneamente, assiste-se a uma extensão geográfica dos locais da extração do mineral : além do Canadá e da ex-União Soviética, novas jazidas começarão a ser exploradas na América do Sul, na África e na Austrália. E serão instaladas inúmeras fábricas de fibrocimento por todo o mundo, movimento esse estreitamente associado ao crescimento económico dos países ricos, mas também às evoluções "desenvolvimentistas" dos países do "terceiro mundo".

4 2. Ora, a constatação dos efeitos nefastos do amianto sobre a saúde dos trabalhadores porá em causa evidências, que moldaram as nossas sociedades durante décadas. Com efeito, as pesquisas científicas dirigidas por grandes médicos, tais como o inglês Richard Doll e o norte-americano Irving Selikoff, provocaram um verdadeiro abalo social e político em vários países. Esses estudos, divulgados nos inícios dos anos '60, acabaram por conferir uma nova visibilidade às graves consequências do uso do amianto em ambientes de trabalho : asbestose e mesotelioma, isto é, fibrose e cancro dos pulmões e cancros da pleura, do peritónio e do pericárdio, mas igualmente da laringe, da faringe, do estômago ou dos ovários. Nessa época, já se falava de "catástrofe sanitária", pois os casos que se iam revelando e contabilizando (grande parte tendo a sua génese duas ou três décadas atrás, dada a lenta evolução de certos desses cancros) anunciavam a calamidade que se prolongará até aos nossos dias.

5 3. Mas a denúncia científica, ganhando em importância, e o despertar dos movimentos, nacionais e internacionais, de defesa das vítimas, não deixarão impassível o lobby industrial e económico do amianto. Na verdade, este grupo de interesses desencadeará, estrategicamente, um debate, no qual intervirão também alguns cientistas, concernente à avaliação dos danos resultantes do uso de todos os tipos de amianto.

6 Será deste modo que conseguirá impor a tese segunda a qual os malefícios só se verificariam com a utilização das variedades do amianto anfibólio, enquanto que em relação ao outro tipo de amianto, o amianto crisótilo, dada a especificidade das suas fibras, os efeitos nocivos seriam mínimos. Além disso, acrescenta tal tese, esses efeitos mínimos seriam eliminados através de um uso "controlado" da atividade de extração e de produção do mineral.

7 Se é verdade que, a partir de meados dos anos '70, todos ou quase todos os países tinham proibido o uso ou utilização de todas as variedades do amianto anfibólio; também é verdade que esse tipo de amianto representava $5 \%$ do total utilizado no planeta. Tal proibição exprimirá assim, por um lado, uma tentativa do lobby para dar uma resposta moral aos alertas suscitados pelas pesquisas científicas, e, por outro, o reforço do objetivo de poder continuar, serena e plenamente, a explorar o amianto crisótilo a nível mundial.

8 Com efeito, este paradigma, do "uso controlado (ou em segurança) do amianto crisótilo", será consagrado na Convenção 162 da OIT, de 1986, conquistando, assim, uma forte legitimidade internacional. Assinalemos, também, que o Estado canadiano foi o ator principal da afirmação e da longa manutenção desse paradigma no seio dos fora internacionais (OIT, Convenção de Roterdão, OMC, ...). E para entendermos, ainda melhor, o peso dos interesses económicos no desenrolar das dinâmicas do processo contencioso do amianto, sublinharemos que o Canadá dominou, durante décadas, a produção e as exportações mundiais de amianto - tendo, todavia, adotado na prática o chamado "modelo do duplo padrão", reduzindo gradualmente o seu consumo interno, mas mantendo até há poucos anos, a exportação da quase totalidade da sua produção. 
De qualquer modo, a tese que defende a inofensividade da exposição "controlada" às fibras do amianto da variedade crisotila, foi sendo desmitificada por inúmeros estudos científicos e, infelizmente, também pelos gravíssimos danos causados à saúde e à vida de muitas.os trabalhadoras.es, que se foram tornando cada vez mais visíveis. E, em consequência, os movimentos pela abolição definitiva, sobretudo os dos países europeus, foram obtendo satisfação, pelo menos no que diz respeito à interdição do uso do amianto propriamente dita. Aliás, a União Europeia (Comunidade Europeia) decidiu, através da Diretiva 1999/77 de 26 de junho, que todos os seus Estados-membros passariam a consagrar, na respetiva ordem jurídica, a proibição definitiva do amianto a partir de 2005. Mesmo se alguns Estados, como a França, tinham já adotado tal interdição.

10 4. Os casos apresentados neste dossier revelam, contudo, que alguns protagonistas deste conflito social ainda se mantêm ativos - ora, transformando tal conflito, como no Brasil, em sucessivas brigas jurídico-políticas; ora, como em França, onde a mobilização das associações e dos sindicatos prova como são ainda indispensáveis na defesa dos direitos fundamentais dos trabalhadores neste domínio.

11 A questão do amianto surge-nos, pois, como muito atual : continua a sê-lo em termos de saúde ocupacional, pública e ambiental, e sê-lo-á cada vez mais enquanto problema associado à gestão dos seus resíduos e aos modos de manutenção, reparação, remoção ou demolição de edifícios, instalações e equipamentos em que existe amianto ou materiais que o contenham. E, nestas situações, a questão central é, evidentemente, a da proteção da saúde dos trabalhadores, mas igualmente a defesa da saúde pública.

12 Nesta matéria, Portugal, após a Revolução de abril de 1974, adotará, numa primeira fase, os normativos consagrados em convenções da OIT, entretanto ratificadas ; e, numa fase seguinte, depois da sua adesão às Comunidades Europeias, em 1986, passará a transpor as diretivas comunitárias relativas à questão do amianto. Assim, o Decreto-lei $\mathrm{n}^{\mathrm{o}}$ 101/2005, de 23 de junho, transpõe a diretiva de 1999 já referida, passando Portugal, a partir dessa data, a proibir de modo definitivo o uso do amianto no seu território. $\mathrm{E}$, em seguida, em julho de 2007, será adotada legislação que transpõe a Diretiva $n^{\circ}$ 2003/18-CE, de 27 de março, concernente, precisamente, à proteção dos trabalhadores em obras onde estejam presentes materiais com amianto. Uma legislação de grande importância, e de grande atualidade, uma vez que o Estado português está a ser confrontado com a tarefa de remoção (ou demolição) do fibrocimento nos edifícios públicos, em particular nos estabelecimentos de ensino. Contudo, tal missão tem sido gerida pelos sucessivos governos com grandes dificuldades e inações.

13 Nas dificuldades, intervêm, obviamente, as da devida proteção dos trabalhadores que desempenham tais atividades de supressão do amianto. É bom lembrar, então, os estudos da Ergonomia que evidenciaram a perigosidade dessa atividade, e a necessidade de lhe atribuir a maior atenção ao conceber, de modo preciso e adequado, tanto as normas de segurança como os respetivos equipamentos de proteção (Garrigou, Mohammed-Brahim \& Daniellou, 1998 ; Duarte, Théry \& Ullilen-Marcilla, 2016).

Muito há ainda a fazer para libertar o mundo do amianto... 


\section{BIBLIOGRAFIA}

Duarte, F., Théry, L., \& Ullilen-Marcilla, C. (2016). "Os equipamentos de proteção individual (EPI) : protetores, mas nem sempre" : apresentação do dossier. Laboreal, 12(1). http:// journals.openedition.org/laboreal/2830.

Garrigou, A., Mohammed-Brahim, B., \& Daniellou, F. (1998). Étude ergonomique sur les chantiers de déflocage d'amiante. Rapport final, OPPBTP/DRT.CT3. Bordeaux.

\section{AUTORES}

\section{MARIANNE LACOMBLEZ}

Centro de Psicologia da Universidade do Porto, Faculdade de Psicologia e Ciências da Educação, Universidade do Porto. Rua Alfredo Allen, 4200-135, Porto, Portugal

lacomb@fpce.up.pt

\section{AUGUSTO ROGÉRIO LEITÃO}

Centro Observare, Universidade Autónoma de Lisboa Rua Santa Marta 56, 1169-023 Lisboa \& Faculdade de Economia, Universidade de Coimbra Av. Dr. Dias da Silva 165 3004-512 Coimbra, Portugal 